\title{
The Association of Various Placental Lesions with Perinatal Outcome in Preterm Births
}

\author{
Ashwini Sarode ${ }^{1}$, Anil R Joshi ${ }^{2}$, Anjali S Kulkarni ${ }^{3}$ \\ ${ }^{1}$ Assistant Professor, Department of Pathology, Government Medical College, Aurangabad. \\ ${ }^{2}$ Professor and Head, Department of Pathology, Government Medical College, Aurangabad. \\ ${ }^{3}$ Assistant Professor, Department of Pathology, Government Medical College, Aurangabad.
}

Corresponding Author: Anil R Joshi

\begin{abstract}
Objective: Present study was designed to identify various lesions in placenta and investigate their impact on neonatal and perinatal outcome and also to determine the frequency of various inflammatory lesions in placenta.

Materials and Methods: Placentae of 60 singleton non-anomalous preterm births were examined at Department of pathology at Tertiary care centre. Complete placental examination including both macroscopic and microscopic examination with the help of Haematoxylin and Eosin staining done. Thereafter placental lesions were classified according to Redline criteria for classification of placental pathology. Thereafter placental lesions were correlated with perinatal mortality and neonatal morbidity in early neonatal period. The relevant clinical details were collected from the obstetric clinical records and neonatal clinical records.
\end{abstract}

Result: We found placental vascular processes as most frequent $(73.33 \%)$ pathological lesion in our study. Most common inflammatory lesion in our study was chorioamnionitis (15\%). Also among placentae of stillbirths, placental vascular lesions were predominant finding present in $85.7 \%$ of placentae of stillbirths. Other lesions found in placentae of stillbirths were Immune inflammatory lesions, maternal floor infarction and placenta accreta.

Out of total placentae with vasculopathy, $19.2 \%$ cases developed neonatal sepsis, in chorioamnionitis group $66.6 \%$ live births were having sepsis.
In present study we observed higher frequency of resuscitation in babies with placentae having chorioamnionitis.

Discussion: This study revealed that the placental pathological findings appear to be correlated with perinatal mortality and early neonatal morbidity. So, examination of the preterm placentae gains importance in early determination of morbidity in infants. Placental findings can help neonatologist in routine diagnosis and management.

Key Words: Placenta, Placental pathology, Preterm births, Perinatal outcome

\section{INTRODUCTION}

Placenta is the least understood and one of the most important human organs, not only for the health of a woman and her fetus during pregnancy but also for the lifelong health of both. The placenta is the link between the mother and the fetus. Thus, disturbed placental function can lead to various adverse fetal outcomes. ${ }^{1,2}$ The histopathological examination of the placenta may provide crucial information. It is possible to identify placental or fetal conditions that can be recurrent or inherited. $^{3}$

Placental pathology has been implicated in the pathogenesis of preterm neonatal morbidity. Maternal disease affecting the placental circulation or intrinsic placental pathology can lead to fetal growth restriction or stillbirth. ${ }^{4}$

Present study was designed to identify various lesions in placenta and 
investigate their impact on neonatal and perinatal outcome and also to determine the frequency of various inflammatory lesions in placenta.

\section{MATERIALS AND METHODS}

This is a prospective observational study carried out at our Tertiary care centre duration from 2016 to 2018. This study included 60 placentae for histopathological examination. Only placentas that from preterm deliveries (whose gestational age is above 20 weeks and below 37 weeks) were selected for study. Placentas from the preterm births were studied for any evidence of pathology. Mortality including stillbirth and neonatal morbidity in early neonatal period was analysed.

Placentae from multiple gestation pregnancies, newborns with birth defects were excluded. Placentae from fetus about which clinical details were not available and placentae with improper fixation were also excluded from the study. Complete placental examination including both macroscopic and microscopic examination with the help of Haematoxylin and Eosin staining was done. Amsterdam group consensus criteria and definitions were used to diagnose various lesions ${ }^{5}$. Lesions were classified according to classification by Redline et $\mathrm{al}^{6}$. Placental lesions are studied in accordance with perinatal outcome by ascertaining placental lesions in main three groups-Placental vascular processes, chorioamnionitis, No pathology. Placental vascular processes consist of maternal stromal vascular processes and fetal stromal vascular processes. Chorioamnionitis includes both infective and immune causes of chorioamnionitis, subgroup of placental immune inflammatory lesions. Placentae without any pathology were ascertained to group 'no pathology'.

\section{RESULT AND OBSERVATIONS}

A. Clinical Characteristics - In Our study Mean birth weight was 1771.2 gm.65\% $(n=39)$ babies were born alive while $35 \%$ $(n=21)$ babies were stillborn. Out of total livebirths $10.2 \% \quad(n=4)$ babies were small for gestational age.

Extreme preterm births $(<28$ weeks) were $11.67 \%(\mathrm{n}=7)$.Very preterm births (28-31 weeks) were $16.66 \%(n=10)$, Moderate preterm births (32-33 weeks) were $20 \%$. Late preterm births were $51.67 \%$ $(\mathrm{n}=31)$.

B. Placental examination- Shape of the placenta was circular 60\% ( $\mathrm{n}=36)$ and $40 \%$ $(n=24)$ were of oval shape. Mean placental thickness was $2.65 \mathrm{~cm}$. Eccentric insertion of cord was the commonest i.e. $(61.6 \%, \mathrm{n}=37)$ while marginal insertion was least common i.e. $6.6 \%(n=4)$, rest cases being those with central cord insertion.

Table No. I Placental lesions according to classification by Redline et al $^{6}$

\begin{tabular}{|l|l|l|}
\hline Placental lesion & n & Percentage \\
\hline Placental vascular processes (PVP) & 44 & $73.33 \%$ \\
\hline $\begin{array}{l}\text { Placental Inflammatory Immune Processes } \\
\text { (PIIP) }\end{array}$ & 14 & $23.33 \%$ \\
\hline Maternal floor infarction (MFI) & 6 & $10 \%$ \\
\hline Placenta Accreta (PA) & 3 & $5 \%$ \\
\hline No pathology & 10 & $16.66 \%$ \\
\hline
\end{tabular}

Total may exceed as more than one lesion were coexisting in same case.

Placental vascular processes were most frequent $(73.33 \%, \mathrm{n}=44)$ pathological lesion, which were subdivided into maternal $(n=30)$ and foetal $(n=33)$ stromal vascular lesions. There were 3 cases of developmental vascular lesions, while 29 cases of maternal vascular malperfusion. Fetal stromal vascular developmental lesions and fetal vascular malperfusion were found in 20 cases each and loss of integrity in fetal circulation was found in 12 cases.

Placental immune inflammatory lesions were subdivided into two groups' infectious lesions and immune lesions. 9 cases of infectious type and 5 were immune type. Infectious lesions included 7 cases with acute chorioamnionitis and one case each of acute deciduitis, chorionic vasculitis and acute intervillositis were found. In immune lesions we found two cases each of chronic villitis, chronic deciduitis and chronic chorioamnionitis. Total exceed as 
more than one lesion coexisting in same cases.

\section{Frequency of caesarean section and placental pathology-}

In our study we found highest frequency of caesarean section when placentae are affected by vasculopathy i.e.43.2 \% $(\mathrm{n}=19)$ and lowest in chorioamnionitis group i.e.33.3.\% $(n=3) .40$ $\%$ cases with no pathology also undergone caesarean section.

\section{Placental lesions and perinatal outcome -}

Placental vascular lesions were most common findings in stillbirth cases $(85.7 \%)$ while second most common lesion was immune inflammatory lesion. Acute chorioamnionitis was the most common immune inflammatory lesion $19(n=4)$ in placentae of stillbirth.

Table no.II - Placental lesions in stillbirth cases

\begin{tabular}{|l|l|l|}
\hline Placental pathology & $\begin{array}{l}\text { No. of placentae in } \\
\text { stillbirth }\end{array}$ & $\begin{array}{l}\text { Percent } \\
\text { age }\end{array}$ \\
\hline Placental vascular lesions & 18 & $85.70 \%$ \\
\hline $\begin{array}{l}\text { Placental immune } \\
\text { inflammatory lesions }\end{array}$ & 10 & $47.60 \%$ \\
\hline Maternal floor infarction & 4 & $19 \%$ \\
\hline Placenta accrete & 1 & $4.70 \%$ \\
\hline
\end{tabular}

Table-III- Comparison of placental findings with Neonatal parameters

\begin{tabular}{|l|l|l|l|}
\hline Placental pathology & Mean GA & Neonatal sepsis & Babies who required resuscitation \\
\hline No pathology $(\mathrm{n}=10)$ & 34.6 & $0 \%(0)$ & $20 \%(2)$ \\
\hline Placental vascular processes $(\mathrm{n}=26)$ & 31.8 & $19.2 \%(5)$ & $61.5 \%(16)$ \\
\hline Chorioamnionitis(n=3) & 30.8 & $66.6 \%(2)$ & $66.6 \%(2)$ \\
\hline
\end{tabular}

GA-Gestational age. Figures in bracket shows number of cases.

Mean gestational age was highest with placentae without any abnormality whereas found lowest with placentae with chorioamnionitis. Highest proportion of babies with placentae showing chorioamnionitis $(66.6 \%)$ found to be susceptible to neonatal sepsis and also required resuscitation after birth $(66.2 \%)$.

\section{PHOTOGRAPHS:}

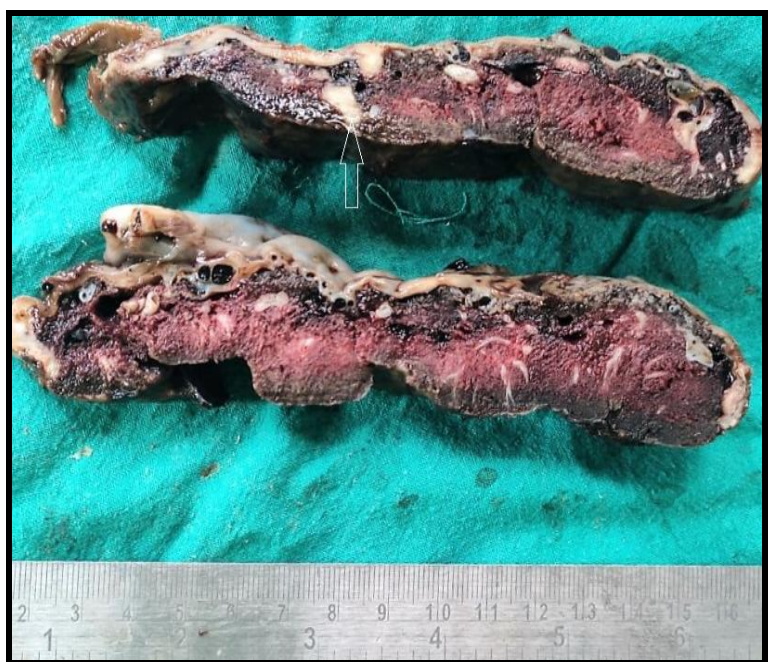

FIG.1- Photograph showing cut section of placenta showing multiple whitish yellow plaques of fibrinoid deposition.

\section{Placental vascular processes- i) Maternal stromal vascular processes-}

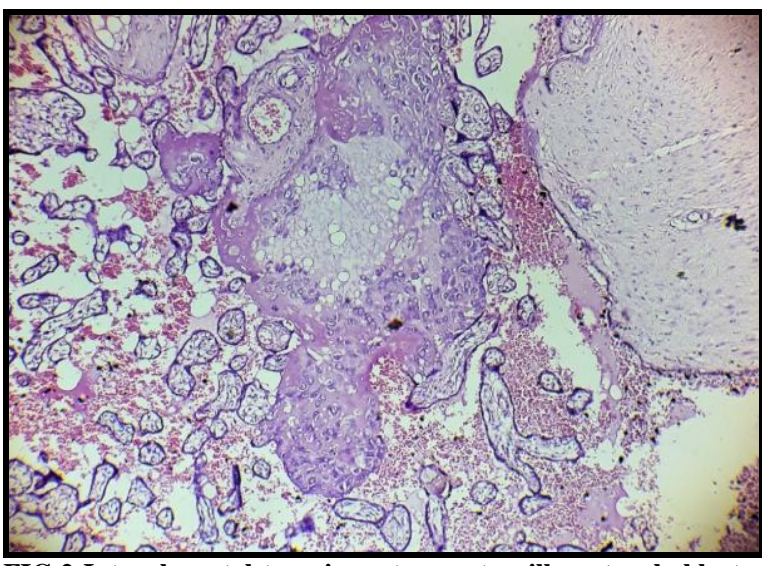

FIG.2-Intraplacental-type immature extravillous trophoblast(10XView, Hematoxylin and eosin stain):Photomicrograph showing Large trophoblast island embedded in fibrinoid, with central cystic degeneration (pseudocyst-formation) containing pink-staining, non-haemorrhagic fluid.

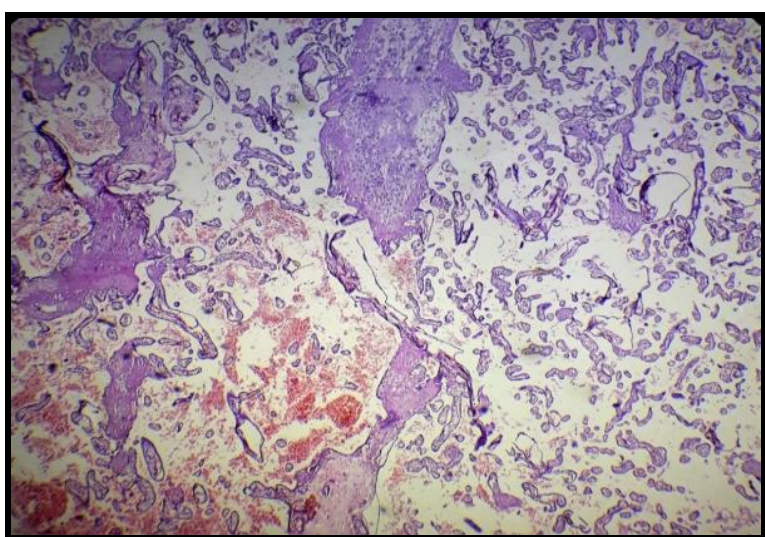

FIG.3-Distal villous hypoplasia (10X View, Hematoxylin and eosin stain)-Photomicorgraph shows paucity of distal villi.Villi are slender,long and elongated with widening of intervillous space. 


\section{Placental vascular processes- ii) Fetal stromal vascular processes}

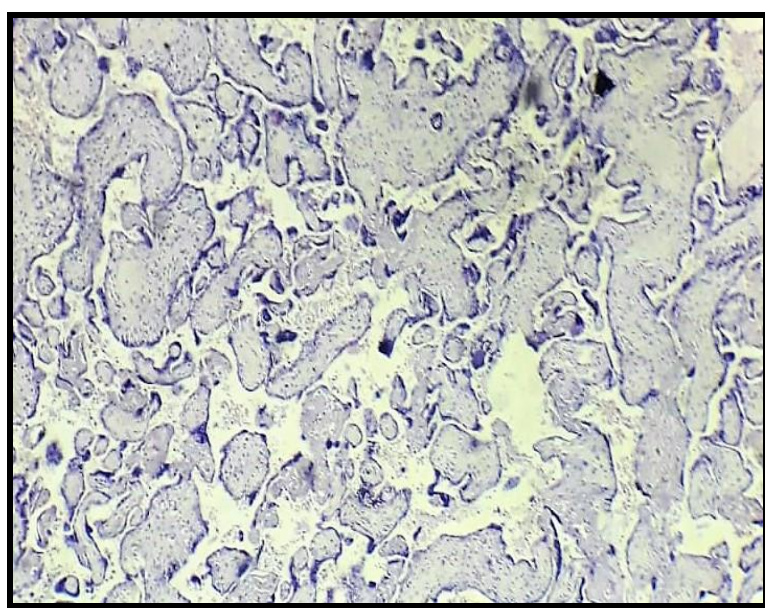

FIG.4-Avascular villi (10X View, Hematoxylin and eosin stain)- Photomicorgraph showing total loss of villous capillaries and hyaline fibrosis of villous stroma.

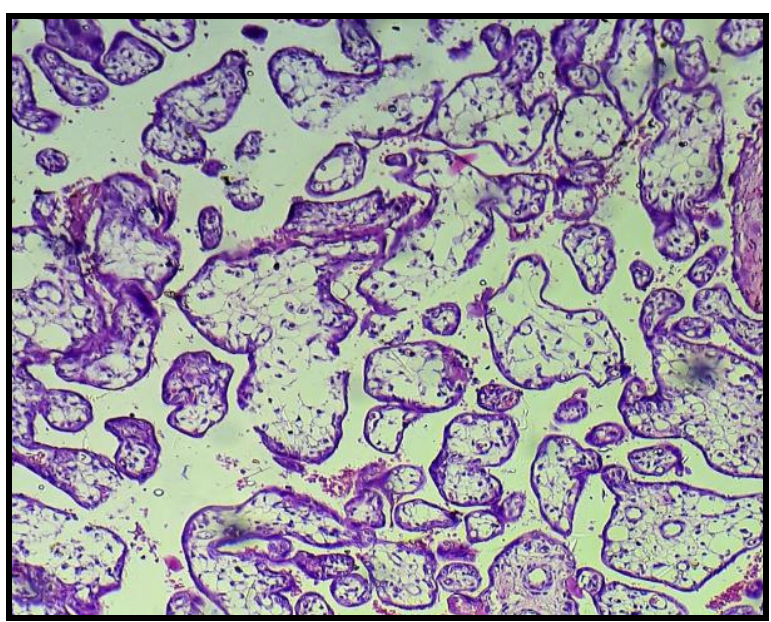

FIG.5-Villous Oedema (10X View, Hematoxylin and eosin stain) - Photomicorgraph showing enlargement of the chorionic villi with edema fluid, abundant stroma and histiocytic infiltrates.

\section{Placental inflammatory immune}

\section{processes-}

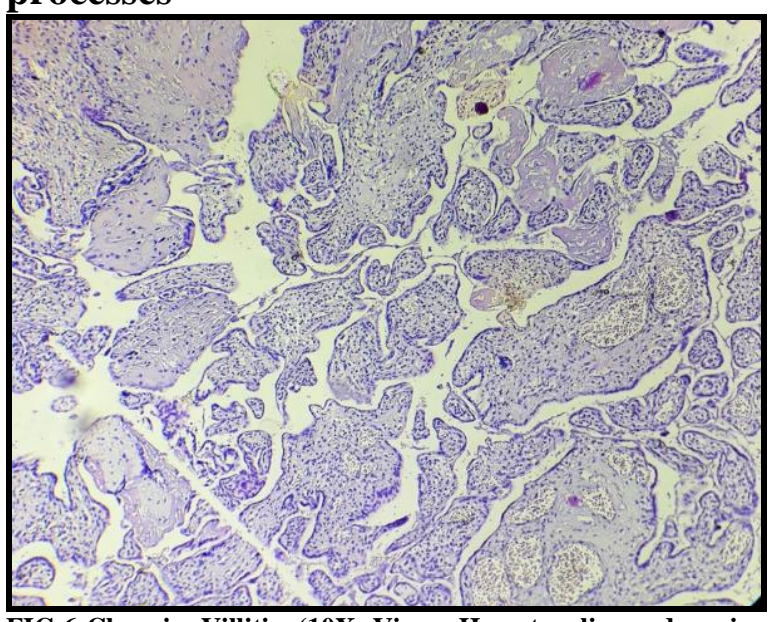

FIG.6-Chronic Villitis (10X View, Hematoxylin and eosin stain) - Photomicorgraph showing chorionic villi with inflammatory infiltrates of lymphocytes and few histiocytes.

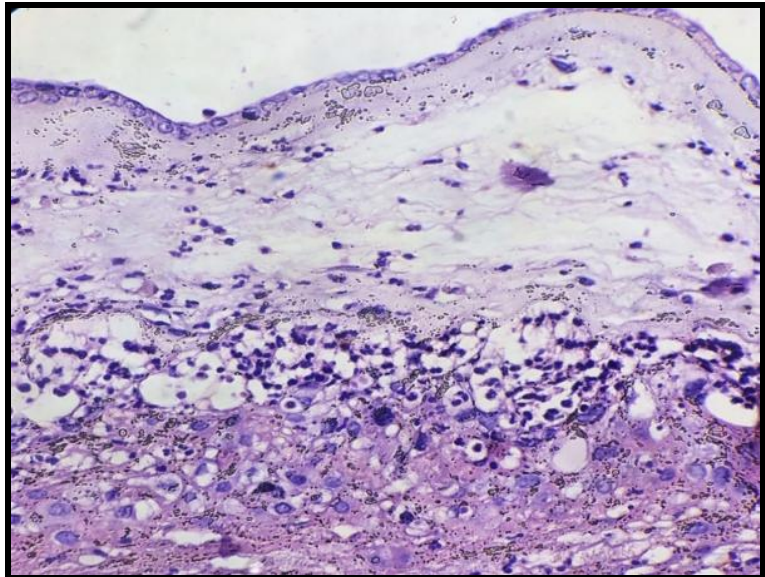

FIG.7-Acute Chorioamnionitis (40X View, Hematoxylin and eosin stain) - Photomicorgraph showing diffuse infiltrates comprised predominantly of polymorphs and few lymphocytes, plasma cells and few histiocytes in chorion and amniotic connective tissue.

\section{OTHER PLACENTAL PROCESSES-}

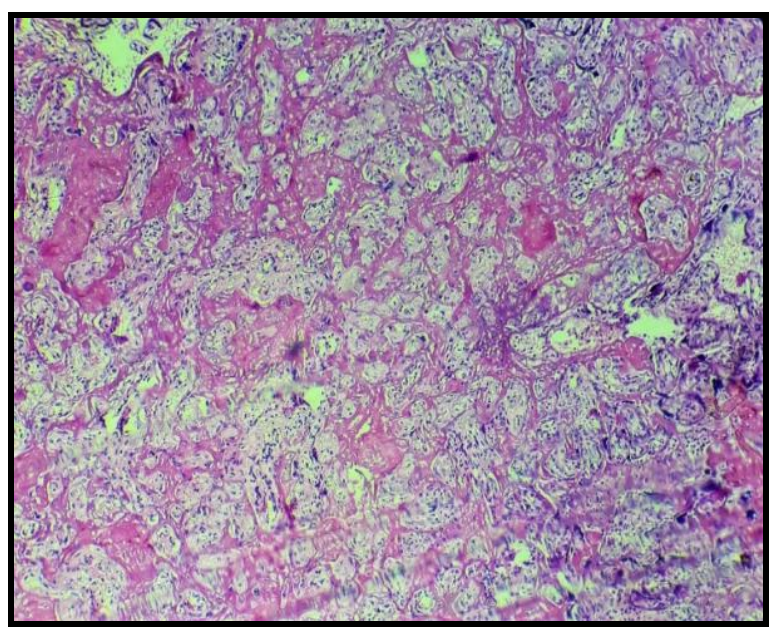

FIG.8-Massive perivillous fibrin deposition (10X View, Hematoxylin and eosin stain)- Photomicorgraph shows massive perivillous eosinophilic fibrin deposition with atrophic villi.

\section{DISCUSSION}

There is variability in definitions used in Placental Pathology Groupings in various studies of placentae. Many studies in literature have discussed placental lesions in subgroups. In this study we have discussed preterm placental pathology in accordance with classification by Redline et al and also studied for any association between placental pathology and neonatal outcomes by ascertaining these lesions in three main group's i.e. Placental vascular processes, Chorioamnionitis and No pathology. Neonatal outcome was studied in accordance with mean Gestational age at 
birth, frequency of sepsis and requirement of resuscitation at birth.

\section{A. Clinical characteristics-}

Jamal et $\mathrm{al}^{7}$ found frequency of late preterm births, moderate preterm births. Very preterm births similar to our study. Purisch SE et $\mathrm{al}^{8}$ also mentioned more frequency of preterm birth after 34 weeks gestational age. Out of total live births, $10.2 \%$ babies were small for gestational age. CAKER U et $\mathrm{al}^{9}$, Beaudet et $\mathrm{al}^{10}$ and Levy et $\mathrm{al}^{11}$ reported frequency of SGA as $13.7 \%$, $18.9 \%$ and $8.8 \%$ respectively which is similar to our result. In present study out of 60 births, $65 \%(n=39)$ were live births and $35 \%(n=21)$ were stillbirths while Vinnars et $\mathrm{al}^{12}$ reported $62.87 \%(\mathrm{n}=105)$ live births out of 167 births while $37.12 \% \quad(n=62)$ were stillbirths.

\section{B. Placental characteristics-}

Circular shape of placenta was most common as noticed in $60 \%$ cases which were comparable to Qureshi et $\mathrm{al}^{13}$ who found $77 \%$ cases with circular shape and $23 \%$ with oval shape. Raghunath et $\mathrm{al}^{14}$ also reported $94 \%$ cases of placentae with circular shape.

In the present study mean placental thickness was $2.65 \mathrm{~cm}$. It was found $1.612 \mathrm{~cm}$ and $2.324 \mathrm{~cm}$ in study by Zaidi $\mathrm{MT}^{15}$ et al and Qureshi et $\mathrm{al}^{13}$ respectively.

\begin{tabular}{|c|c|c|c|c|c|}
\hline & Naeye RL et al ${ }^{16}$ & Qureshi et al $^{13}$ & Eastman et al $^{17}$ & Ashoka A et al ${ }^{18}$ & Present study \\
\hline Central & $28 \%$ & $7 \%$ & $18 \%$ & $32 \%$ & $31.6 \%$ \\
\hline Eccentric & $56 \%$ & $88 \%$ & $73 \%$ & $51 \%$ & $61.6 \%$ \\
\hline Marginal & $15 \%$ & $5 \%$ & $7 \%$ & $15 \%$ & $6.6 \%$ \\
\hline Velamentous & $2 \%$ & 0 & $1.25 \%$ & $2 \%$ & $0 \%$ \\
\hline
\end{tabular}

Eccentric insertion of the cord was the most common type in our study $(61.6 \%)$.

Similarly Naeye RL et al ${ }^{16}$, Qureshi et $\mathrm{al}^{13}$, Eastman et $\mathrm{al}^{17}$ and Ashoka $\mathrm{A}$ et al ${ }^{18}$ also found eccentric insertion of umbilical cord as most common type of cord insertion. Placenta microscopic examination-

\section{i. Placental vascular processes-}

We have divided our cases in main three groups. Total placental vascular processes were $73.3 \%$ out of total. CAKIR $\mathrm{U}$ et $\mathrm{al}^{9}$ who were also divided study cases in main three groups, got $53.9 \%$ cases with placental vascular processes. Placental vascular lesions were most common lesions in our study as similar with CAKER $U$ et $\mathrm{al}^{9}$. We again subdivided placental vascular processes in two main groups. Maternal stromal vascular lesions were noticed in $50 \%$ placentae and fetal stromal vascular lesions in $55 \%$ placentae. Total of two exceeds as more than one lesion was present in some placentae. After literature study we observed that data is lacking about more subdivided lesions in preterm births. Roescher et $\mathrm{al}^{19}$ who got $60 \%$ placentae with maternal stromal vascular lesions. In literature there is deficiency of data about fetal stromal vascular lesions. We observed most of the studies discuss about fetal vascular malperfusion instead of main group fetal stromal vascular lesions. So, we divided fetal stromal vascular lesions in three groups. In that, $16.6 \%$ cases consisted of fetal vascular malperfusion. Roescher et $\mathrm{al}^{19}$ reported $15 \%$ cases and Chisholm et $\mathrm{al}^{20}$ reported $20 \%$ cases with fetal vascular malperfusion. Data is lacking about more subdivided lesions in placenta in preterm births.

\section{ii. Placental immune inflammatory lesions-}

We found $15 \% \quad(n=9)$ cases with chorioamnionitis and $23.3 \%$ with placenta inflammatory immune lesions. Most of the studies discussed about frequency of chorioamnionitis rather than total placental inflammatory immune processes. CAKIR U et $\mathrm{al}^{9}$ found $12.3 \% \quad(\mathrm{n}=35)$ placentae with chorioamnionitis. They did not specified about total inflammatory immune lesions. Vik T et $a^{21}$ found $7 \%(\mathrm{n}=5)$ placentae with chorioamnionitis and $18 \%$ with Placental 
inflammatory immune lesions. Anblagan D et $\mathrm{al}^{22}$ reported $14.4 \%$ with chorioamnionitis.

According to Ocheke $\mathrm{AN}$ et $\mathrm{al}^{23}$ frequency of histopathological chorioamnionitis may vary from 11.5 to $57.3 \%$. Thus our result of chorioamnionitis is comparable with CAKIR et al, Anblagan $\mathrm{D}$ et $\mathrm{al}^{22}$ and Ocheke AN et $\mathrm{al}^{23}$ studies and findings of Placental Inflammatory Immune Processes (PIIP) are comparable with study by Vik $\mathrm{T}$ et $\mathrm{al}^{21}$.

iii. Maternal floor infarction (MFI)/ Perivillous fibrin (oid) deposition-

Aggarwal R et $\mathrm{al}^{24}$ (2016) found $6.6 \%$ with MFI out of 60 placentae while Beaudet et $\mathrm{al}^{10}$ reported $11 \%$ of MFI out of 1296 placentae. In our study $10 \%$ of MFI out of 60 total cases.

\section{Frequency of caesarean section and placental pathology-}

Our study is comparable with Ogunyemi et $\mathrm{al}^{25}$ and CAKIR $\mathrm{U}$ et al study regarding frequency of caesarean section being highest when placentae are affected by vasculopathy. We found $43.2 \%$ cases with vasculopathy had undergone caesarean section. CAKIR U et $\mathrm{al}^{9}$ found $91.5 \%$ cases and Ogunyemi et $\mathrm{al}^{25}$ found $57 \%$ cases with vasculopathy had undergone caesarian section.

In our study the delivery by caesarean sections were found to be lowest in the Chorioamnionsitis group as also reported in CAKIR U et $\mathrm{al}^{9}(51.4 \%)$ and Ogunyemi et $\mathrm{al}^{25}(43 \%)$.

\section{Placental findings in stillbirths cases-}

In placentae of stillbirth cases, vascular lesions were the most common findings $(85.7 \%)$, second most common was inflammatory immune lesions $(47.6 \%)$,then placentae with maternal floor infarction (19\%) and $4.7 \%$ cases with placentae accrete.

Pinar et $\mathrm{al}^{26}$ also found vascular lesions were the most common findings $(61.1 \%)$,thereafter immune inflammatory lesion was the second most common (14.9\%) maternal floor infarction in $9.2 \%$ cases.

The most common placental inflammatory lesion was acute chorioamnionitis in our study (19\%) which was similar to Pinar et $\mathrm{al}^{26}(30.4 \%)$ and Bukowski et $\mathrm{al}^{27}$ study (24.5\%).Chorionic vasculitis were present in $4.7 \%$ cases. Bukowski et $\mathrm{al}^{27}$ found $3 \%$ cases with chorionic vasculitis. So our findings were comparable with Bukowski et $\mathrm{al}^{27}$.

\section{E. Comparison of placental findings with Neonatal parameters}

\begin{tabular}{|c|c|c|c|c|}
\hline Placental pathology & Study & Mean GA(week) & Sepsis (\%) & Resuscitation (\%) \\
\hline \multirow[t]{2}{*}{ No pathology } & CAKIR U et $\mathrm{al}^{9}$ & 32.5 & $8.3 \%$ & $11.4 \%$ \\
\hline & Present study & 34.6 & $0 \%$ & $20 \%$ \\
\hline \multirow[t]{2}{*}{ Placental vascular processes $(n=26)$} & CAKIR U et $\mathrm{al}^{9}$ & 31.3 & $9.8 \%$ & $22.8 \%$ \\
\hline & Present study & 31.8 & $19.2 \%$ & $61.5 \%$ \\
\hline \multirow[t]{3}{*}{ Chorioamnionitis } & CAKIR U et $\mathrm{al}^{9}$ & 28.5 & $82.8 \%$ & $25.7 \%$ \\
\hline & Anblagan D. et $\mathrm{al}^{22}$ & - & $62 \%$ & - \\
\hline & Present study & 30.8 & $66.6 \%$ & $66.6 \%$ \\
\hline
\end{tabular}

Mean gestational age was highest in group without any pathology and lowest in group with placentae showing chorioamnionitis, and these findings were comparable with study by CAKIR U et al.

We found frequency of neonatal sepsis was highest in babies with accompanying placenta having chorioamnionitis $(66.6 \%)$ similar finding was reported by CAKIR U et al.
CAKIR $U$ et al found increased frequency of resuscitation requirement in babies with placentae having chorioamnionitis $(25.7 \%)$ while In present study we also observed highest frequency of resuscitation in babies with placentae having chorioamnionitis (66.6\%).Difference in frequency may be due to difference in sample size. 


\section{CONCLUSION}

Among all preterm births, most preterm births occur in late preterm phase (34-36 weeks). Circular shape of placenta and eccentric insertion of umbilical cord was more common. Prominent microscopic pathology in placentae of preterm births was placental vascular processes, placental immune inflammatory lesions and maternal floor infarction. Placental vascular processes/ vasculopathy were the most frequent lesion (73.3\%). Frequency of immune inflammatory lesions was $23.3 \%$ in placentae of preterm births. Chorioamnionitis was the most common inflammatory lesion. Frequency of chorioamnionitis (including infectious and immune cause) was $15 \%$.

Frequency of caesarean section was highest when placentae are affected by vasculopathy lesions.

In stillborn preterm also, placental vascular processes were most frequently present. Among all inflammatory lesions, acute chorioamnionitis was the most common lesion in preterm stillbirths. Infants delivered by mothers with placental chorioamnionitis were found to be more preterm and have more risk of neonatal morbidities like sepsis in neonatal period.

Such placental lesions are easily detectable by histopathological examination and these placental findings can help neonatologist in routine diagnosis and management. However, there is a need of optimising the importance of placental examination among clinicians as well as it is also important to establish a routine protocol of placental examination accompanying neonatal care as followed in abroad countries. Studies on placental pathology and maternal morbidities are available. As compared, such data in view of neonatal morbidities is less. So, larger study on placental pathology in this view is also recommended.

\section{Acknowledgement: None}

Conflict of Interest: None

\section{Source of Funding: None}

\section{Ethical Approval: Approved}

\section{REFERENCES}

1. Korteweg FJ, Erwich JJ, Holm JP, Ravisé $\mathrm{JM}$, van der Meer J, Veeger $\mathrm{NJ}$ et al. Diverse placental pathologies as the main causes of fetal death. Obstetrics \& Gynecology. 2009 Oct 1;114(4):809-17.

2. SHeazell A. The placenta and adverse pregnancy outcomes-opening the black box?. InBMC pregnancy and childbirth 2015 Dec (Vol. 15, No. 1, p. A5). BioMed Central.

3. van Vliet EO, de Kieviet JF, van der Voorn JP, Been JV, Oosterlaan J, van Elburg RM. Placental pathology and long-term neurodevelopment of very preterm infants. American journal of obstetrics and gynecology. 2012 Jun 1;206(6):489-e1.

4. Mehta R, Nanjundaswamy S, Shen-Schwarz S, Petrova A. Neonatal morbidity and placental pathology. The Indian Journal of Pediatrics. 2006 Jan 1;73(1):25-8.

5. Khong TY, Mooney EE, Ariel I, Balmus NC, Boyd TK, Brundler MA, Derricott H, Evans MJ, Faye-Petersen OM, Gillan JE, Heazell AE. Sampling and definitions of placental lesions: Amsterdam placental workshop group consensus statement. Archives of pathology \& laboratory medicine. 2016 May 25;140(7):698-713.

6. Redline RW. Classification of placental lesions. American journal of obstetrics and gynecology. 2015 Oct 1;213(4):S21-8.

7. Jamal S, Srivastava R. A retrospective analytical study of the epidemiology and causes of preterm birth. Int $\mathrm{J}$ Reprod Contracept Obstet Gynecol. 2017 Nov 23;6(12):5453-7.

8. Purisch SE, Gyamfi-Bannerman C. Epidemiology of preterm birth. InSeminars in perinatology 2017 Nov 1 (Vol. 41, No. 7, pp. 387-391). WB Saunders.

9. Cakir U, Yildiz D, KAHVECIOĞLU D, Okulu E, Alan S, ERDEVE Ö et al. Placenta, Secret Witness of Infant Morbidities: The Relationship Between Placental Histology and Outcome of the Premature Infant. Turkish Journal of Pathology. 2019 Jan 1;1(1).

10. Beaudet L, Karuri S, Lau J, Magee F, Lee SK, von Dadelszen P. Placental pathology 
and clinical outcomes in a cohort of infants admitted to a neonatal intensive care unit. Journal of Obstetrics and Gynaecology Canada. 2007 Apr 1;29(4):315-23.

11. Paz-Levy D, Schreiber L, Erez O, Goshen S, Richardson J, Drunov V, Chacham OS, Shany E. Inflammatory and vascular placental lesions are associated with neonatal amplitude integrated EEG recording in early premature neonates. PloS one. 2017 Jun 23;12(6):e0179481.

12. Vinnars MT, Papadogiannakis N, Nasiell J, Holmström G, Westgren M. Placental pathology in relation to stillbirth and neonatal outcome in an extremely preterm population: a prospective cohort study. Acta obstetricia et gynecologica Scandinavica. 2015 Jun;94(6):584-90.

13. Qureshi S, Singh DJ, Fulwaria DM, Yadav DOP. A study to find out association between morphometry of placenta and neonates profile at tertiary care teaching hospital, Bikaner.International journal of medical science and education.2018:p.35863.

14. Raghunath G, Shmi V, Shenoy V. Clinically relevant morphology and morphometry of Placenta. JCDR 2011; 5(2):282-286.

15. Zaidi MT, Arshad M, Vasenwala SM, Faruqi NA, Khan AA, Khan S, ZAIDI M, ARSHAD M, VASENWALA S, FARUQI N, KHAN A. Histomorphometry of preterm and term human placentas. Int. J. Morphol. 2013 Jun 1;31(2):409-13.

16. Naeye RL. Functionally important disorders of the placenta, umbilical cord, and fetal membranes. Human pathology. $1987 \mathrm{Jul}$ 1;18(7):680-91.

17. Eastman,N.J.,Hellman,L.M:William's Obstetrics,ed.13,New York,1966, Appleton Century-Crofts, Inc.

18. Ashoka A, Sarthi M, Basavraj AC, Mahesh TK. Placental pathology and its correlation with immediate feto neonatal outcome. Int $\mathbf{J}$ Contemp Pediatr 2019;6:1108-12.

19. Roescher AM, Hitzert MM, Timmer A, Verhagen EA, Erwich JJ, Bos AF. Placental pathology is associated with illness severity in preterm infants in the first twenty-four hours after birth. Early human development. 2011 Apr 1;87(4):315-9.

20. Chisholm KM, Norton ME, Penn AA, Heerema-McKenney A. Classification of preterm birth with placental correlates. Pediatric and Developmental Pathology. 2018 Nov;21(6):548-60.

21. Vik T, Redline R, Nelson KB, Bjellmo S, Vogt $\mathrm{C}, \mathrm{Ng} \mathrm{P}$ et al. The Placenta in Neonatal Encephalopathy: A Case-Control Study. The Journal of pediatrics. 2018 Nov 1;202:77-85.

22. Anblagan D, Pataky R, Evans MJ, Telford EJ, Serag A, Sparrow S, Piyasena C, Semple SI, Wilkinson AG, Bastin ME, Boardman JP. Association between preterm brain injury and exposure to chorioamnionitis during fetal life. Scientific reports. 2016 Dec 1;6:37932.

23. Ocheke AN, Ocheke IE, Agaba PA, Imadde GE, Silas OA, Ajetunmobi Ol et al. Maternal and neonatal outcomes of histological chorioamnionitis. Journal of the West African College of Surgeons. 2016 Jul;6(3):1.

24. Aggarwal A, Pahwa S. Evaluation of the role of CRP as an early predictor of chorioamnionitis in PPROM. International Journal of Reproduction, Contraception, Obstetrics and Gynecology.;7(4):1352.

25. Ogunyemi D, Murillo M, Jackson U, Hunter $\mathrm{N}$, Alperson B. The relationship between placental histopathology findings and perinatal outcome in preterm infants. The Journal of Maternal-Fetal \& Neonatal Medicine. 2003 Jan 1;13(2):102-9.

26. Pinar H, Goldenberg RL, Koch MA, HeimHall J, Hawkins HK, Shehata B, Abramowsky C, Parker CB, Dudley DJ, Silver RM, Stoll B. Placental findings in singleton stillbirths. Obstetrics and gynecology. $2014 \mathrm{Feb} ; 123(20$ 1):325.

27. Bukowski R, Hansen NI, Pinar H, Willinger M, Reddy UM, Parker CB, Silver RM, Dudley DJ, Stoll BJ, Saade GR, Koch MA. Altered fetal growth, placental abnormalities, and stillbirth. PloS one. 2017 Aug 18;12(8):e0182874.

How to cite this article: Sarode A, Joshi AR, Kulkarni AS. The association of various placental lesions with perinatal outcome in preterm births. International Journal of Research and Review. 2021; 8(5): 357-364. DOI: https://doi.org/10.52403/ijrr.20210545 